\title{
Inhibition of Nitric Oxide Production and Nitric Oxide Synthase Gene Expression in LPS Activated RAW 264 .7 Macrophages by Thyme Oleoresin from Thymus vulgaris
}

\author{
Chidambaram Shunmugam Kumar Mangal ${ }^{1}$, Roy Anitha ${ }^{2 *}$, Thangavelu Lakshmi ${ }^{2}$ \\ 'Graduate Student, Saveetha Dental College, Saveetha Institute of Medical and Technical Sciences, Saveetha University, Chennai, Tamil Nadu, INDIA. \\ ${ }^{2}$ Faculty of Pharmacology, Saveetha Dental College, Saveetha Institute of Medical and Technical Sciences, Saveetha University, Chennai, Tamil Nadu, INDIA.
}

\begin{abstract}
Objective: To evaluate the effect of Thyme oleoresin on nitric oxide production and nitric oxide synthase gene expression in RAW264.7 macrophage cell lines. Methods: The efficacy of Thyme oleoresin at different concentrations $(3.175-150 \mu \mathrm{g} / \mathrm{ml})$ was determined on nitric oxide production in RAW264.7 cells macrophages. The optical density was measured at 540 $\mathrm{nm}$ with a microplate reader. RT - PCR was used to examine the expression of the iNOS gene in activated macrophages. The Statistical analysis of the data was carried out by Dunnett's following one way ANOVA and Posthoc comparisons in Graph pad Prism 5.0 software version. Results: Thyme oleoresin at its tested concentrations exhibited dose - dependent decrease in the production of NO. The $\mathrm{IC}_{50}$ value was $24.24 \mu \mathrm{g} / \mathrm{ml}$. LPS stimulated RAW macrophages strongly up regulated the iNOS gene expression levels. Thyme oleoresin at three different concentration, $12.5 \mu \mathrm{g} / \mathrm{ml}, 25 \mu \mathrm{g} / \mathrm{ml}$ and $50 \mu \mathrm{g} / \mathrm{ml}$, significantly suppressed the iNOS levels compared to that of LPS
\end{abstract}

treatment only. Conclusion: Thyme oleoresin extract may be used for its anti-inflammatory effect as it could significantly suppress the iNOS gene expression as well as the production of NO.

Key words: Anti inflammatory, Macrophage cell line, Nitric oxide, Thyme oleoresin.

Correspondence

Dr. Anitha Roy, Associate Professor, Department of Pharmacology, Saveetha Dental College and Hospitals, Saveetha Institute of Medical and Technical Sciences, Saveetha University, Chennai, Tamil Nadu, INDIA.

Phone: (Off) +91-44-26801580-87, + 91-9840787458

Email: anitharoy2015@gmail.com

DOI: 10.5530/jyp.2018.10.104

\section{INTRODUCTION}

Nature has provided a complete store-house of remedies to cure all aliments of mankind. ${ }^{1}$ Medicinal plants are believed to be an important source of new chemical substances with potential therapeutic effects. ${ }^{2-4}$ Thyme (Thymus vulgaris, family Labiatae) is a medicinal plant which has been used as a folk medicine against asthma, arteriosclerosis, colic, bronchitis, coughs, diarrhea, rheumatism and cancer. Thyme has been used to promote perspiration. ${ }^{5}$

Nitric oxide is considered as a pro-inflammatory mediator that induces inflammation due to its over production in abnormal situations. In mammalian cells NO is synthesized during the conversion of L-arginine to L-citrulline which is catalyzed by the isoform of nitric oxide synthase (NOS). ${ }^{6}$ The inducible NOS [iNOS]) is expressed by a variety of factors such as inflammatory cytokines, TNF- $\alpha$ and lipopolysaccharide which binds to the heme group of soluble guanylyl cyclase to generate cGMP. Activated cGMP then binds specifically to transcription factors, protein kinases and phosphodiesterases to elicit downstream effects. NO can also act by directly modifying proteins or contributing to the oxidation of proteins and lipids leading to normal as well as pathophysiologic functions. ${ }^{7-10} \mathrm{NO}$ inhibitors represent important therapeutic advance in the management of inflammatory diseases because $\mathrm{NO}$ is involved in the pathogenesis of inflammatory disorders of the joint, gut and lungs. ${ }^{6}$ The aim of the present study was to evaluate the effect of thyme oleoresins on nitric oxide production and nitric oxide synthase gene expression in macrophage cell lines.

\section{MATERIALS AND METHODS}

\section{Chemicals}

Lipopolysaccharide (LPS), Phenol free Dulbecco's modified Eagle medium (DMEM), MTT, Dimethyl sulphoxide (DMSO), phosphate buffer saline

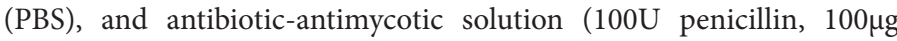
streptomycin, and $0.25 \mu \mathrm{g}$ amphotericin $\mathrm{B}$ per $\mathrm{ml}$ ) were purchased from Sigma-Aldrich. Fetal bovine serum was purchased from GIBCO/BRL Invitrogen.

\section{Plant extract}

Thyme oleoresin was obtained from Synthite Industries Limited, Kerala as gratis.

\section{Cell culture}

Macrophage RAW 264.7 cells were obtained from the NCCS, Pune with Passage no 16. Cells were cultured in phenol red-free Dulbecco's modified Eagle medium (DMEM) supplemented with 100 units/ml penicillin, $100 \mu \mathrm{g} / \mathrm{ml}$ streptomycin and $10 \%$ heat-inactivated fetal bovine serum at $37^{\circ} \mathrm{C}$ with $5 \% \mathrm{CO}_{2}$. Cells were washed with DMEM medium and detached with $0.25 \%$ trypsin-EDTA. The cells were seeded at a density of $5 \times 10^{5} \mathrm{cells} /$ well in 24 well plate and incubated for $18 \mathrm{~h}$ at $37^{\circ} \mathrm{C}$ and $5 \%$ $\mathrm{CO}_{2}$. Then media of each well were aspirated and fresh FBS-free DMEM media were replaced. Different concentrations of Thyme extract (3.175$150 \mu \mathrm{g} / \mathrm{mL}$ ) were prepared in FBS-free DMEM to give a total volume of 
$500 \mu \mathrm{l}$ in each well of a microtiter plate. The cells were co - incubated with $1 \mu \mathrm{g} / \mathrm{ml}$ of LPS for $24 \mathrm{~h}$.

\section{Estimation Nitric oxide (NO)}

The presence of nitrite, a stable oxidized product of nitric oxide (NO), was determined in cell culture media using Griess reagent. $50 \mu \mathrm{l}$ of supernatant from the test culture was mixed with $50 \mu \mathrm{l}$ of $1 \%(\mathrm{w} / \mathrm{v})$ sulphanilic acid in $5 \%(\mathrm{v} / \mathrm{v})$ phosphoric acid in a 96 -well plate, followed by incubation for $10 \mathrm{~min}$ at room temperature. After that $50 \mu \mathrm{l} 0.1 \%(\mathrm{w} / \mathrm{v})$ $\mathrm{N}$-1-naphthyl ethylenediamine $\mathrm{HCl}$ in distilled water was added and incubated for $10 \mathrm{~min}$ at room temperature. The optical density at $540 \mathrm{~nm}$ was measured with a microplate reader. The $\mathrm{NO}$ concentration was calculated by comparison with a $\mathrm{NaNO}_{2}(0-100 \mu \mathrm{M})$ standard curve. The final concentration of DMSO was adjusted to less than $0.1 \%$ for all treatments. The results were expressed as inhibition of $\mathrm{NO}$ production compared to the control (LPS) using: ([nitrite $]_{c}-\left[\right.$ nitrite $\left._{\mathrm{t}}\right) /\left[\text { nitrite }_{\mathrm{c}} \text {, where [nitrite }\right]_{\mathrm{c}}$ and $[\text { nitrite }]_{\mathrm{t}}$ are the nitrite concentration in the control and test sample, respectively. ${ }^{11,12}$

\section{RNA Isolation and q - PCR Analysis}

To determine whether thyme extract inhibits NO production at the level of transcription, RT - PCR was used to examine the expression of the iNOS gene in activated macrophages. RAW macrophages were treated with $12.5 \mu \mathrm{g} / \mathrm{ml}, 25 \mu \mathrm{g} / \mathrm{ml}$ and $50 \mu \mathrm{g} / \mathrm{ml}$ of Thyme extract with $1 \mu \mathrm{g} / \mathrm{ml}$ of LPS and incubated for $24 \mathrm{~h}$. Total RNA was isolated using TRIzol reagent (Invitrogen) according to the manufacturer's protocol, and $2 \mu \mathrm{g}$ of RNA was used for complementary DNA synthesis using M-MLV reverse transcriptase (Promega, Madison, WI, USA). Quantitative real-time polymerase chain reaction ( $\mathrm{q}-\mathrm{PCR}$ ) was performed in an $\mathrm{ABI}$ 7500 Real-Time System with SYBR Green PCR Master Mix (Takara). Reactions were initiated with an initial incubation at $50^{\circ} \mathrm{C}$ for $2 \mathrm{~min}$ and $94^{\circ} \mathrm{C}$ for $10 \mathrm{~min}$, followed by 40 cycles of $94^{\circ} \mathrm{C}$ for $5 \mathrm{~s}, 60^{\circ} \mathrm{C}$ for $15 \mathrm{~s}$, and $72^{\circ} \mathrm{C}$ for $10 \mathrm{~s}$. The relative gene expression levels were calculated using the $2-\Delta \Delta \mathrm{Ct}$ method. The specific primer sequences used were given below and $\beta$-actin was used as an internal reference gene between different samples.

INOS: Forward:5'-ATGTCCGAAGCAAACATCAC-3'

Reverse: 5'-TAATGTCCAGGAAGTAGGTG-3'

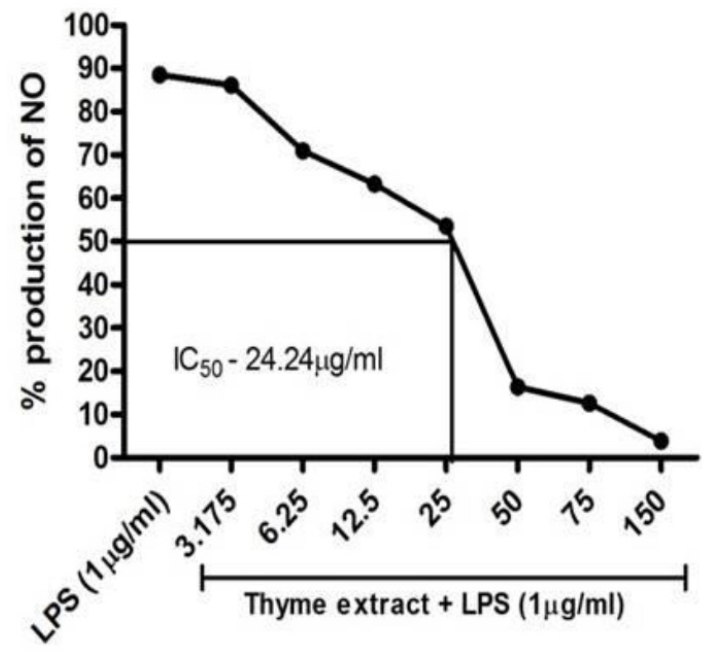

Figure 1: Graphical representation of effect of Thyme extract on production of NO production in LPS stimulated RAW 264.7 macrophages.

\section{Statistical analysis}

Data obtained from the experiments were expressed as Mean \pm SEM $(n=3)$. The Statistical analysis of the difference between the groups was evaluated by Dunnett's following one way ANOVA Posthoc comparisons in Graph pad Prism 5.0 software version. $p<0.001, p<0.01$ and $p<0.05$ were considered to be statistically significant.

\section{RESULTS}

\section{Effect of Thyme oleoresin on NO production}

Nitrite production was dependent on the activating state of the cells. LPS unstimulated macrophages (Control) for $24 \mathrm{~h}$ produced lowest levels of NO, whereas LPS stimulated group showed $89.61 \pm 0.47 \%$ of NO. The effect of thyme extract on nitric oxide production in RAW macrophages was dose dependant. Thyme oleoresin at its tested concentrations exhibited dose - dependent decrease in the production of NO. At 3.175 $\mu \mathrm{g} / \mathrm{ml}$ of thyme oleoresin showed $86.13 \pm 0.47$ of $86.13 \pm 0.47 \%$ where as at $150 \mu \mathrm{g} / \mathrm{ml}$ it produced only $3.84 \pm 0.82 \%$ of nitric oxide. The $\mathrm{IC}_{50}$ value was found to be $24.24 \mu \mathrm{g} / \mathrm{ml}$ (Figure 1).

\section{Gene Expression of iNOS}

LPS stimulated RAW macrophages strongly up-regulated the iNOS gene expression levels. In the presence of thyme extract at three different doses of $12.5 \mu \mathrm{g} / \mathrm{ml}, 25 \mu \mathrm{g} / \mathrm{ml}$ and $50 \mu \mathrm{g} / \mathrm{ml}$, the iNOS level was significantly suppressed, compared to that of LPS treatment only (Figure 2).

\section{DISCUSSION}

The present study results indicate that thyme oleoresin has good NO inhibitory activity. With increase in the concentration of the extract, the nitrous oxide level continues to decrease by inhibiting the effect of iNOS. Hence, thyme oleoresin may be used as an anti-inflammatory agent as it can inhibit one of the major pro-inflammatory constituent in certain disease conditions.

$\mathrm{NO}$ is known for its physiological role including immune defense against microorganisms but excess production of $\mathrm{NO}$ is associated with various diseases such arthritis, diabetes, stroke, septic shock, autoimmune, chronic inflammatory diseases and atherosclerosis. In the pathogenesis of several neurodegenerative diseases, excessive NO production has been identified as one of the major causative reasons. ${ }^{13}$ Inducible nitric

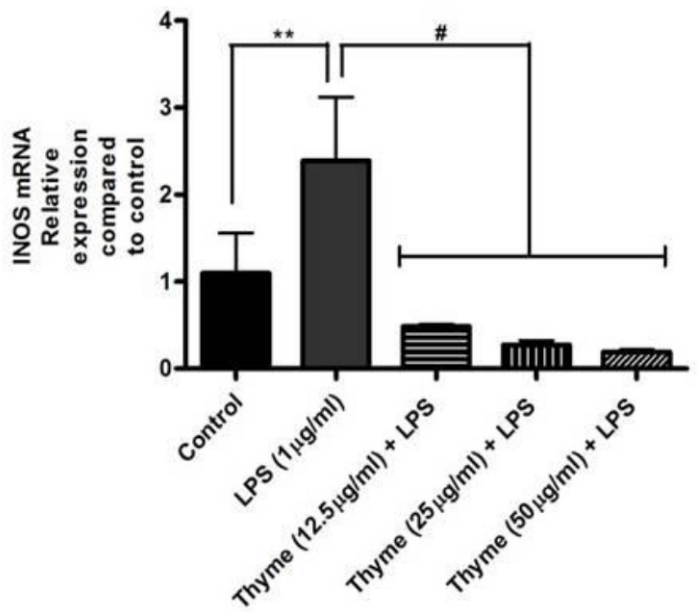

Figure 2: Effect of Thyme extracton LPS - stimulated iNOS expression in RAW 264.7 macrophages. 
oxide synthase (iNOS) is responsible for the large production of nitric oxide which in turn is responsible for the vasodilation and hypotension observed during septic shock and inflammation. Hence, inhibitors of iNOS may be useful candidates for the treatment of inflammatory diseases accompanied by the overproduction of NO. ${ }^{14}$

Inflammation is actually a defense and protection to multiple harmful stimuli, however; when it is self-amplified and uncontrolled it leads to pathogenesis of a wide variety of inflammatory illness. It involves pro-inflammatory cytokines such as nitrous oxide and it acts as an important biological response toward injury. Several studies have demonstrated the properties of various compounds from plants which tend to possess rich pharmacological properties that play beneficial roles in many conditions including inflammation-related diseases. ${ }^{15,16} \mathrm{NO}$ has the property to modify or generate intercellular signals and thus it has an effect on immune cells, tumour cells and the cells of different tissues or organs. In the present study, the effect of thyme on NO production on LPS stimulated Raw 264.7 macrophage cell lines was carried out and has shown a dose dependent inhibitory effect on nitric oxide production which is indicative of its anti-inflammatory effect. Hence, this extract might be used in conditions where, excessive NO production may be a reason and can be treated in a natural way.

Natural plant compounds which are able to suppress the production of inflammatory mediators from activated macrophages can act as potential anti-inflammatory agents. Many researchers have explored different plants for their anti-inflammatory potential. Solanum nigrum Linn is reported to have anti-inflammatory activity on both acute and sub-acute stages of inflammation. ${ }^{17}$ Solanum melongena and Solanum macrocarpon extracts have shown inhibitory effect on $\mathrm{NO}$ production in lipopolysaccharide (LPS)-stimulated RAW 264.7 cells. ${ }^{18}$ Phytoconstituents present in plants such as phenols, triterpenes, tannins, anthraquinones, and flavonoids may be responsible for these anti-inflammatory properties. ${ }^{19}$ Similarly, P.alliacea could reduce inflammation in RAW264 macrophages. It suppressed the oxidative stress and the induction of various pro-inflammatory mediators in RAW264.7 macrophages through NF-B inactivation. ${ }^{20}$

\section{CONCLUSION}

Thyme oleoresin showed a significant decrease in production of pro-inflammatory mediator NO and suppression iNOS gene expression even when enhanced with LPS. Hence, thyme may be used in optimum concentration in particular dosage form for inflammatory conditions after further validation.

\section{ACKNOWLEDGEMENT}

The authors thank Synthite industries private Limited for providing Thyme oleoresin as a gift sample for carrying out this project. Also express gratitude to Ms Parameswari, Senior Research Fellow, Sri Ramachandra Medical College and Research Institute, Chennai for interpreting the results.

\section{CONFLICT OF INTEREST}

The authors declare no conflict of interest.

\section{ABBREVIATIONS}

q-PCR: Quantitative real-time polymerase chain reaction; iNOS: inducible Nitric Oxide Synthase; LPS: Lipopolysaccharide; DMEM: Dulbecco's modified Eagle medium; MTT: 3-(4,5-dimethylthiazol-2-yl)-2,5-diphenyltetrazolium bromide; DMSO: Dimethyl sulphoxide; PBS: Phosphate Buffer Saline; FBS: Fetal Bovine Serum.

\section{REFERENCES}

1. Kokate CK, Purohit AP, Gokhale SB. Textbook of Pharmacognosy. Nirali Prakasan: Pune. 2002;18:1-4.

2. Ashwini S, Anitha R. Anti hyperglycemic activity of Caralluma fimbriata- An in vitro approach. Pharmacogn Mag. 2017;13(Suppl S3):499.

3. Anitha R, Geetha RV. In vitro $\alpha$-Amylase and $\alpha$-Glucosidase Inhibitory Activities of The Ethanolic extract of Dioscorea villosa Tubers. Int. J Pharma Bio Sci. 2013;4(4):49-54

4. Sarah S, Dhanraj G, Anitha R. Anxiety and Aromatherapy a review. International Journal Pharmacology Biological Sciences. 2016;7(3):267-73.

5. Simon JE, Chadwick AF, Craker LE. Herbs: An Indexed Bibliography. 1971-1980. The Scientific Literature on Selected Herbs, and Aromatic and Medicinal Plants of the Temperate Zone. Archon Books. 1984;770.

6. Sharma JN. Al-Omran A, Parvathy SS. Role of nitric oxide in inflammatory diseases. Inflammo pharmacology. 2007;15(6):252-9.

7. Abramson SB. Nitric oxide in inflammation and pain associated with osteoarthritis. Arthritis Res Ther. 2008;10(Suppl 2):S2.

8. Weinberg JB, Fermor B, Guilak F. Nitric oxide synthase and cyclooxygenase interactions in cartilage and meniscus: relationships to joint physiology, arthritis and tissue repair. Subcell Biochem. 2007;42:31-62.

9. Murad F. Nitric oxide and cyclic GMP in cell signalling and drug development N Engl J Med. 2006;355(19):2003-11.

10. Makchuchit $S$, Itharat A, Tewtrakul S. Antioxidant and Nitric Oxide Inhibition Activities of Thai Medicinal Plants. J Med Assoc Thai. 2010;93(Suppl. 7):S227-35.

11. Green LC, Wagner DA, Glogowski J, Skipper PL, Wishnok J S, Tannenbaum SR. Analysis of nitrate, nitrite, and $[15 \mathrm{~N}]$ nitrate in biological fluids. Analytical Biochemistry. 1982;126(1):131-8.

12. Diouf P, Stevanovic T, Cloutier A. Study on chemical composition, antioxidant and anti-inflammatory activities of hot water extract from Picea mariana bark and its proanthocyanidin-rich fractions. Food Chem. 2009;113(4):897-902.

13. Yuste JE, Tarragon E, Campuzano CM, Ros-Bernal F. Implications of glial nitric oxide in neurodegenerative diseases. Front Cell Neurosci. 2015;9:322.

14. YangEJ, YimEY, SongG, KimGO, HyunCG. Inhibition of nitric oxide production in lipopolysaccharideactivated RAW 264.7 macrophages by Jeju plant extracts. Interdiscip Toxicol. 2009;2(4):245-9.

15. Ghasemian M, Owlia S, Owila MB. Review of Anti-Inflammatory Herbal Medicines. Adv Pharmacol Sci. 2016;2016:9130979. doi:10.1155/2016/9130979.

16. Souza NC, de Oliveira JM, Morrone MDS, Albanus RD, Amarante MDSM, Camillo CDS, et al. Antioxidant and Anti-Inflammatory Properties of Anacardium occidentale Leaf Extract. Evid based Complement Alternat Med. vol. 2017; Article ID 2787308, 8 pages, 2017. doi:10.1155/2017/2787308.

17. Aryaa A, Viswanathswamy AH. Effect of Solanum nigrum Linn on Acute and Sub-Acute Models of Inflammation. J Young Pharm. 2017;9(4):566-70.

18. Ling Ng RF, Abidin NZ, Shuib AS, Ali DAI .Inhibition of nitric oxide production by Solanum melongena and Solanum macrocarpon on RAW 264.7 cells. Front Life Sci. 2015;8(3):241-8

19. Nworu CS, Akah PA, Okoye FBC, Toukam DK, Udeh1 J, Esimone CO. The leaf extract of Spondias mombin $L$. displays an anti-inflammatory effect and suppresses inducible formation of tumor necrosis factor- $\alpha$ and nitric oxide (NO) $\mathrm{J}$ Immunotoxicol. 2011;8(1):10-6.

20. Gutierrez RMP, Hoyo-Vadillo C. Anti-inflammatory Potential of Petiveria alliacea on Activated RAW264.7 Murine Macrophages. Pharmacogn Mag. 2017;13(Suppl 2):S174-8.

\footnotetext{
Article History: Submission Date : 18-04-2018 ; Revised Date : 02-07-2018; Acceptance Date : 27-07-2018.

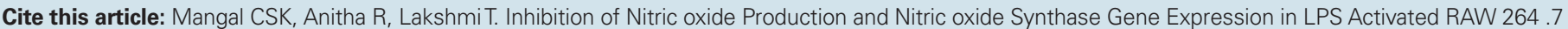
Macrophages by Thyme oleoresin from Thymus vulgaris. J Young Pharm. 2018;10(4):481-3.
} 